\title{
MALT1 Inhibitor JNJ-67856633
}

National Cancer Institute

\section{Source}

National Cancer Institute. MALT1 Inhibitor INJ-67856633. NCI Thesaurus. Code C160147.

An orally bioavailable inhibitor of mucosa-associated lymphoid tissue lymphoma translocation protein 1 (MALT1), with potential antineoplastic activity. Upon administration, MALT1 inhibitor JNJ-67856633 targets, binds to, and prevents the activity of MALT1. This inhibits MALT1-dependent signaling, reduces interleukin-10 (IL-10) and upregulates interferon (IFN). This results in the inhibition of Janus kinase/signal transducers and activators of transcription (JAK/STAT) signaling and nuclear factor-kappa B (NF-kB) signaling, induces apoptosis, and inhibits tumor cell growth of MALT1expressing tumor cells. MALT 1 belongs to the caspase family of proteases and is the active component of the CARD11-BCL10-MALT1 (CBM) signaling complex. It plays an essential role in B- and T-lymphocyte activation and is over-activated in certain tumor cells. 